\title{
ESTADOS CONTABLES DE LOS PARTIDOS POLÍTICOS COMO INSTRUMENTO PARA LA EFECTIVA TRANSPARENCIA Y ACCOUNTABILITY EN LA RENDICIÓN DE CUENTAS ELECTORALES
}

\section{ACCOUNTING DEMONSTRATIONS OF POLITICAL PARTIES AS AN INSTRUMENT FOR THE EFFECTIVE TRANSPARENCY AND ACCOUNTABILITY IN THE ELIGIBILITY OF ELECTORAL ACCOUNTS}

\author{
Juedir Viana Teixeira \\ Universidad Candido Mendes \\ Rio de Janeiro, Brasil \\ juedir@me.com
}

Artur Angelo Ramos Lamenha

Universidad Federal de Alagoas

Maceió, Brasil

artur.lamenha@gmail.com

\author{
Matheus Costa Correa \\ Universidad Federal de Alagoas \\ Maceió, Brasil \\ matheuscc1996@gmail.com
}

João Vinicius Santos Correia de Melo

Sociedad de Ensino Universitário do Nordeste

Maceió, Brasil

jvscm93@hotmail.com

Fecha de recepción: 16/11/2019 - Fecha de aprobación: 14/02/2020

DOI: https://doi.org/10.36995/j.visiondefuturo.2020.24.02.001.es

\section{RESUMEN}

Este artículo tiene como fin presentar la importancia de la evidencia contable en la responsabilidad y transparencia de las cuentas de los partidos políticos, sobre todo en relación a la rendición de cuentas de la utilización de los recursos del fondo partidario. Como pregunta de investigación se tiene: Cuentas y candidatos con situación irregular y grupos de partidos políticos mediante los estados contables ¿presentan una relación con la distribución del fondo partidario y requeriría de una mayor accountability? Para tal problema se estableció como objetivo general verificar la necesidad de la elaboración de estados contables más precisos y confiables para la promoción de la transparencia, y como objetivos específicos, discutir la legislación bajo el punto de vista contable, así como comprender el impacto de la elaboración parcial de los estados en lo que respecta a las cuentas juzgadas como irregulares y a grupos de partidos políticos de acuerdo a la difusión de sus estados. Para ello, se utilizó la investigación bibliográfica, documental y estadística para el análisis e interpretación de los datos extraídos del Tribunal de Cuentas, de los Tribunales Electorales y de la Legislación sobre el tema.

Se concluye que existe una correlación positiva entre el número de cuentas irregulares, el número de personas con una rendición irregular de cuentas y grupos de partidos políticos con la distribución del fondo partidario y que la legislación específica de rendición de cuentas electorales, así como las normas del Consejo Federal de Contabilidad, pueden permitir una mejor

\footnotetext{
"Visión de Futuro" Año 17, Volumen No 24 N², Julio - Diciembre 2020 - Pág 1 - 19

URL de la Revista: http://visiondefuturo.fce.unam.edu.ar/index.php/visiondefuturo/index

URL del Documento: https://visiondefuturo.fce.unam.edu.ar/index.php/visiondefuturo/issue/view/18

ISSN 1668 - 8708 - Versión en Línea

E-mail: revistacientifica@fce.unam.edu.ar
}

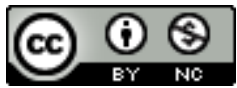

Los trabajos publicados en esta revista están bajo la licencia Creative Commons Atribución- 1 NoComercial 2.5 Argentina 
transparencia y control social con prácticas de Accountability / Responsabilidad mediante los estados Contables.

PALABRAS CLAVE: Partidos Políticos; Accountability; Estados Contables.

\section{ABSTRACT}

This article aims to present the importance of the accounting evidence in responsibility and transparency of the political parties' accounts, especially in relation to the accountability of the use of the resources of the party fund. As a research question we have: Do accounts and candidates with irregular status and groups of political parties through the financial statements have a relationship with the distribution of the party fund and would require greater accountability? For this problem, it was established as a general objective to verify the need for the elaboration of more accurate and reliable accounting statements for the promotion of transparency, and as specific objectives, to discuss the legislation from the accounting point of view, as well as to understand the impact of the partial elaboration of the states with regard to the accounts judged as irregular and to groups of political parties according to the diffusion of their statements. For this, bibliographic, documentary and statistical research was used for the analysis and interpretation of the data extracted from the Court of Auditors, the Electoral Courts and the Legislation about this issue.

It is concluded that there is a positive correlation between the number of irregular accounts, the number of people with irregular accountability and political party groups with the distribution of the party fund and that the specific legislation about election accountability, as well as the rules of the Federal Accounting Council, can allow better transparency and social control with Accountability practices through the Accounting Statements.

KEYWORDS: Political Parties; Accountability; Financial Statements.

\section{INTRODUCCIÓN}

La Ciencia Contable proporciona información útil y detallada, siempre que sea elaborada de acuerdo con los dictámenes de las normas contables, para que el usuario interno y externo de la organización, ya sea con fines de lucro o no, tenga plena consciencia de las alteraciones financieras, económicas y patrimoniales.

\footnotetext{
"Visión de Futuro" Año 17, Volumen No 24 N², Julio - Diciembre 2020 - Pág. 1 - 19

URL de la Revista: http://visiondefuturo.fce.unam.edu.ar/index.php/visiondefuturo/index

URL del Documento: https://visiondefuturo.fce.unam.edu.ar/index.php/visiondefuturo/issue/view/18

ISSN 1668 - 8708 - Versión en Línea

E-mail: revistacientifica@fce.unam.edu.ar
} 
En esta investigación, la mencionada ciencia será abordada en el ámbito del Tercer Sector, más específicamente en los partidos políticos. En estas entidades sin fines de lucro, la contabilidad posee peculiaridades en lo que respecta a la parte técnica, no obstante, en su esencia, permanece la misma, esto es, debe "captar, registrar, acumular, resumir e interpretar los fenómenos que afectan las situaciones patrimoniales, financieras y económicas" (Ludícibus et al., 2010, p.15).

El tecnicismo particular aplicado a los partidos políticos se encuentra anclado en la Interpretación Técnica General (ITG) - R1 - Entidad sin fines de lucro. Sin embargo, la legislación que dispone sobre los partidos políticos no se encuentra alineada por completo con los dictámenes presentes en la ITG 2002 - R1, particulares e indispensables para la transparencia de las cuentas de dichas organizaciones. Desde el punto de vista legal, la Ley № 9.096/1995, reglamentada por la Resolución № 23.546/2017, dispone parcialmente sobre los Estados Contables, exigiendo solamente dos, de un total de cinco, para el envío a la Justicia Electoral y su posterior publicación.

De esta manera, la accountability o responsabilidad de los partidos políticos tiende a perder calidad, ya que no están obligadas a seguir, en su totalidad, las reglas contables dispuestas por el Consejo Federal de Contabilidad (CFC) y, consecuentemente, disminuye la oportunidad de recibir sanciones de la Justicia Electoral. De acuerdo con la Ley N9096/1995, son no aptos para recibir el Fondo Partidario aquellos partidos políticos considerados insolventes frente a la Justicia Electoral y, por ello, sujetos a sanción impuesta por el art. 37 - A de la Ley que los reglamenta, o sea, acarreando la suspensión de nuevas cuentas hasta que transcurra el tiempo de la insolvencia.

Frente a la preocupación con la divergencia de las obligaciones y, consecuentemente, el perjuicio a la transparencia de la información necesaria para la sociedad, se formula la siguiente pregunta: Cuentas y candidatos con situación irregular y grupos de partidos políticos mediante los estados contables ¿presentan una relación con la distribución del fondo partidario y requeriría de una mayor accountability? Buscando responder a esta pregunta, se estableció como objetivo general: verificar la necesidad de elaboración de estados contables más precisos y confiables para la promoción de la transparencia, y como objetivos específicos: discutir la legislación desde el punto de vista contable, así como comprender el impacto de la elaboración parcial de los estados en lo que se refiere a las cuentas juzgadas como irregulares y grupos de partidos políticos de acuerdo con la difusión de sus propios estados contables.

Este estudio se justifica mediante la discusión del papel de la contabilidad en el efectivo control de gastos públicos, políticas de control de los fondos partidarios y la mejora de la

\footnotetext{
"Visión de Futuro" Año 17, Volumen N² 24 N², Julio - Diciembre 2020 - Pág. 1 - 19

URL de la Revista: http://visiondefuturo.fce.unam.edu.ar/index.php/visiondefuturo/index

URL del Documento: https://visiondefuturo.fce.unam.edu.ar/index.php/visiondefuturo/issue/view/18

ISSN 1668 - 8708 - Versión en Línea

E-mail: revistacientifica@fce.unam.edu.ar
} 
accountability en los partidos políticos. Bajo el punto de vista académico, sirve también para contribuir con nuevos estudios en el área del control y auditoría de las cuentas públicas, electorales y de los actores involucrados en los eventos económicos electorales.

El trabajo se divide en cuatro partes, donde la introducción se encuentra en el primero; una breve discusión teórica sobre la legislación partidaria y las normas contables en el segundo; la metodología, presentación y análisis de los datos en el tercero; y las consideraciones finales en el último.

\section{DESARROLLO}

\section{Principales Referencias teóricas}

De acuerdo con la Ley $N^{\circ}$ 9.096, del 19 de septiembre de 1995, que reglamenta y normaliza los Partidos Políticos, en sus disposiciones preliminares los conceptualiza objetivamente y establece en su art. $1^{\circ}$ :

El partido político, persona jurídica de derecho privado, se destina a asegurar, en interés del régimen democrático, la autenticidad del sistema representativo y a defender los derechos fundamentales definidos en la Constitución Federal. (Ley 9.096, 1995, art. 1).

Son organizaciones sociales formadas por personas voluntarias, legalmente autorizadas, con el objetivo de ocupar el poder político. Estas organizaciones representan la libertad de elección del pueblo, el cual ejerce la democracia a través del voto y la legitimidad de las elecciones. El poder político, una vez alcanzado, permite que los partidos defiendan los intereses e ideales de aquellos ciudadanos que depositaron su confianza y desean la representatividad en el ejercicio del mandato. La estructura y la organización de los partidos políticos se definen también mediante la ley antes citada, que establece que los partidos registrados en el Tribunal Superior Electoral - TSE podrán organizarse en los Estados y Municipios a través de la constitución de directorios definitivos o de comisiones provisionales, ambos reglamentados por el estatuto partidario.

De acuerdo con el $\S 1^{\circ}$ del art. $7^{0}$ de la Ley en cuestión:

Solo se admite el registro del estatuto del partido político que posea carácter nacional, considerándose como tal a aquel que compruebe el apoyo de electores correspondientes a, por lo menos, medio por ciento de los votos en la última elección general para la Cámara de Diputados, sin computar los votos en blanco y los nulos, distribuidos por un tercio o más de los Estados, con un mínimo de un décimo por ciento del electorado que haya votado en cada uno de ellos. (Ley 9.096, 1995, art. 7).

\footnotetext{
"Visión de Futuro" Año 17, Volumen No 24 N² 2, Julio - Diciembre 2020 - Pág. 1 - 19

URL de la Revista: http://visiondefuturo.fce.unam.edu.ar/index.php/visiondefuturo/index

URL del Documento: https://visiondefuturo.fce.unam.edu.ar/index.php/visiondefuturo/issue/view/18

ISSN 1668 - 8708 - Versión en Línea

E-mail: revistacientifica@fce.unam.edu.ar
} 
La soberanía popular es ejercida en las elecciones para cargos políticos mediante elecciones directas para elegir a sus representantes, las cuales contribuyen con la organización de la administración pública, mantenimiento de los derechos de la población y la ejecución de la democracia; luego, la sociedad posee un papel muy importante y mecanismos para controlar, participar, analizar y renovar a las personas políticas, sus conductas, legislación y organización de la máquina del Estado.

Para ello, es esencial que los ciudadanos conozcan la estructura de los partidos, sus fuentes de financiación, cómo se organizan, cómo ejecutan sus operaciones, sobre todo financieras, y cuáles son sus principales obligaciones frente a los órganos competentes. Entre las responsabilidades de un partido político, la rendición de cuentas es un diferencial en el proceso democrático, tomando en cuenta la necesidad de transparentar la real situación del partido frente a la sociedad. De esta manera, aquellos que se mas comprometen en demostrar la información al público tienden a obtener credibilidad en sus promesas.

La rendición de cuentas, también denominada accountability, es el acto de exponer, mediante de informes, la realidad y mostrar su misión a los interesados. En el caso de los partidos políticos, disponer de información fidedigna de la real situación administrativa-financiera de la entidad a la sociedad y a las instituciones y órganos fiscalizadores.

Milani Filho (2009) resalta la importancia de la calidad de la información transmitida, ya que no basta solamente entregar la rendición de cuentas en la fecha determinada por ley. El celo en la realización de los informes es tan importante como la tempestividad en su entrega. Priorizar una característica en detrimento de otra solo refuerza la idea de desprecio por el usuario y por la accountability.

Estos informes poseen un doble carácter, pues atienden a dos usuarios diferentes y con exigencias diferentes. El informe de accountability posee un enfoque vertical y otro horizontal. El carácter vertical de la rendición de cuentas se encuentra íntimamente relacionado con las elecciones y el control de la sociedad en las acciones de los gobernantes que esta elige. El carácter horizontal, por otro lado, se refiere a los agentes estatales que supervisan y punen a otros agentes públicos, en este caso, la Justicia Electoral, al apreciar las cuentas de los gobernantes y sus respectivos políticos.

La accountability vertical se refiere a la necesidad que tienen los representantes de rendir cuentas y someterse al veredicto de la población, siendo su epicentro la elección, que es el instrumento mediante el cual los constituyentes pueden controlar la actividad de sus representantes, pudiendo castigarlos o premiarlos con base en la información relativa a su desempeño (Pontes, 2008, p. 143).

\footnotetext{
"Visión de Futuro" Año 17, Volumen No 24 N², Julio - Diciembre 2020 - Pág. 1 - 19

URL de la Revista: http://visiondefuturo.fce.unam.edu.ar/index.php/visiondefuturo/index

URL del Documento: https://visiondefuturo.fce.unam.edu.ar/index.php/visiondefuturo/issue/view/18

ISSN 1668 - 8708 - Versión en Línea

E-mail: revistacientifica@fce.unam.edu.ar
} 
Oliveira (2009) conceptualiza la accountability horizontal corresponde a mecanismos de control horizontal entre los poderes. Según O’Donnell (1998 apud Pontes, 2008, p. 40) comprende agencias:

La existencia de agencias estatales que tienen el derecho y el poder legal y que se encuentran, de hecho, dispuestas y capacitadas para realizar acciones, que van desde la supervisión de la rutina, las sanciones legales hasta el impeachment contra las acciones 0 emisiones de otros agentes o agencias del Estado que puedan ser calificados como delictivas. (O'donnel, 1998 apud Pontes, 2008, p. 40).

Pontes (2008), al abordar el concepto de accountability horizontal, percibe la función de la Justicia Electoral de mitigar el riesgo de omisión o inexactitud en la rendición de cuentas para contribuir con el proceso democrático.

La participación de la Justicia Electoral ocupa la posición central en la efectividad de la accountability, ya que es mediante la fiscalización de la actividad político-partidaria y de su publicidad, con la disponibilidad de información del proceso de toma de decisiones de cuentas a la población que permite el control de la sociedad. (Pontes, 2008, p.143).

Ambos usuarios de la accountability, actualmente, disfrutan de una facilidad en la evaluación de los informes debido a la evolución tecnológica. La sociedad y la Justicia Electoral lograron tener acceso más rápido a las rendiciones de cuentas de los partidos políticos, facilitando la interacción con las instituciones democráticas. Los medios de comunicación, como la Internet, facilitaron la transparencia y desarrollaron una interacción más rápida entre los interesados en la información.

Actualmente, es utilizado como herramienta para presentar los estados contables, el Sistema de Rendición de cuentas Electorales -SRCE, previsto en la Resolución - TSE №23.553/2017, según el Manual de Operaciones del SRCE - Registro, es un programa desarrollado por la Justicia Electoral para ayudar en la elaboración de la rendición de cuentas de campañas electorales de los candidatos y partidos políticos. De acuerdo con la resolución, la rendición de cuentas ha de ser elaborada mediante el SRCE, que deberá ser instalado en el computador del usuario para completar la información.

Esta herramienta, efectivamente, representó un gran salto para la política partidaria brasileña, en lo que concierne a la rendición de cuentas, tomando en cuenta la utilización de medios electrónicos y dejando de lado el papel. No obstante, el avance de Brasil en esta materia se restringe al software, pues el contenido, en general, transmitido vía SRCE, continúa sin mucha credibilidad.

Melo (2017) realizó una investigación, en la cual analizó los partidos políticos que eligieron representantes para el cargo de concejal en las elecciones de 2016 en el municipio de Rondonópolis/MT, y constató también la fragilidad en la calidad de la información contable proporcionada, pues los partidos apenas cumplían las exigencias legales. Como ya fue

\footnotetext{
"Visión de Futuro" Año 17, Volumen No 24 N², Julio - Diciembre 2020 - Pág. 1 - 19

URL de la Revista: http://visiondefuturo.fce.unam.edu.ar/index.php/visiondefuturo/index

URL del Documento: https://visiondefuturo.fce.unam.edu.ar/index.php/visiondefuturo/issue/view/18

ISSN 1668 - 8708 - Versión en Línea

E-mail: revistacientifica@fce.unam.edu.ar
} 
mencionado en este estudio, existe una divergencia entre la exigencia de la ley y las normas contables editadas por el CFC, lo que genera una perdida inevitable de transparencia.

Para el autor, los partidos políticos aun desarrollan una contabilidad de manera muy aficionada, solamente buscan a través de ella cumplir la legislación electoral vigente y no la utilizan de la mejor manera posible. (Melo, 2017).

La contabilidad y el profesional contable juegan un papel esencial en la transparencia y rendición de cuentas a través de la presentación de los actos y hechos ocurridos en las actividades con el propósito de satisfacer a la sociedad que clama transparencia y buena fe en el uso de los fondos públicos. En el art. 3º la Resolución № 23.546/2017 dispone que los partidos, en su rendición de cuentas, deben designar un profesional habilitado para que la calificación técnica se pase a los procedimientos y se haga fidedigna.

Los fondos públicos son solamente un tipo de ingreso para garantizar el mantenimiento de los partidos políticos. Estos pueden generar caja de diversas otras maneras, siempre que el origen del recurso se ajuste a las modalidades establecidas por el art. $5^{\circ}$ de la Resolución $^{\circ}$ 23.546/2017. Cualquier recurso con origen dispar a las relacionadas en el artículo supra mencionado se considera ilegal o, como mínimo, dudoso y, por ello, debe ser analizado por la Justicia Electoral de manera minuciosa.

En lo que respecta al Fondo Especial de Asistencia Financiera a los Partidos Políticos 'Fondo Partidario, este está constituido por dotaciones presupuestarias, multas y penalidades electorales, recursos financieros legales y donaciones espontaneas privadas, según afirma Silva (1999). La composición de la dotación destinada al Fondo Partidario se guía por la Ley N9.096/1995, art. 38, inciso IV, in verbis:

Art. 38 El Fondo Especial de Asistencia Financiera a los Partidos Políticos - Fondo Partidario - está constituido por:

$[\ldots]$

IV - Dotaciones presupuestarias de la Unión, en valor nunca inferior, cada año, al número de electores inscriptos hasta el 31 de diciembre del año anterior al de la propuesta presupuestaria, multiplicados por treinta y cinco centavos de real, en valores de agosto de 1995 (Ley 9.096, 1995, art. 38).

De acuerdo con el art. 41 - A de la Ley N9.096/1995, del total del Fondo Partidario, 5\% - cinco por ciento - son destacados para la entrega, en partes iguales, a todos los partidos que satisfagan los requisitos constitucionales de acceso a estos recursos y el $95 \%$ - noventa y cinco por ciento - se distribuye en proporción a los votos obtenidos en la última elección general para la Cámara de Diputados. Son considerados aptos para recibir el Fondo partidario, todos aquellos que no transgredan el art. 37 - A de la Ley N9.096/1995, la cual dispone:

\footnotetext{
"Visión de Futuro" Año 17, Volumen No 24 N², Julio - Diciembre 2020 - Pág. 1 - 19

URL de la Revista: http://visiondefuturo.fce.unam.edu.ar/index.php/visiondefuturo/index

URL del Documento: https://visiondefuturo.fce.unam.edu.ar/index.php/visiondefuturo/issue/view/18

ISSN 1668 - 8708 - Versión en Línea

E-mail: revistacientifica@fce.unam.edu.ar
} 
Art. 37 -A. La falta de rendición de cuentas implicará la suspensión de nuevas cuotas del Fondo Partidario mientras perdure la insolvencia y sujetará a los responsables a las penas de la ley (Ley 9.096, 1995, art. 37).

Los depósitos originarios del Fondo Partidario deben ser realizados en cuentas bancarias distintas a la de los demás recursos, según el Art. $6^{\circ}$ Resolución №23.546/2017.

En lo que respecta a los gastos, de acuerdo con Ferrari (2008, p. 86), "son variaciones negativas del patrimonio neto. Entre otras formas, tienen origen en el consumo de bienes y en la utilización de servicios. Tienen como fin, directa o indirectamente, la obtención de ingresos". Los gastos partidarios son establecidos por el art. $17^{\circ}$ de la Resolución n²3.546/2017 de la siguiente manera:

Constituyen gastos partidarios todos los costos y gastos utilizados por el órgano del partido político para su mantenimiento y consecución de sus objetivos y programas (Resolución 23.546, 2017, art 17).

En los partidos políticos, los gastos poseen determinada forma de comprobación, de acuerdo con lo que prevé el Art.18 de la Resolución N²3.546/2017 de la siguiente manera:

La comprobación de los gastos debe ser realizada por medio de un documento fiscal idóneo, sin enmiendas ni borraduras, debiendo constar la fecha de emisión, la descripción detallada, el valor de la operación y la identificación del emisor y del destinatario o de los contrayentes mediante el nombre o razón social, CPF o CNPJ y domicilio (Resolución 23.546, 2017, art 18).

De esta manera, siempre que fueren realizados gastos de los partidos políticos, ya sea por una persona física o jurídica, debe ser proporcionada la documentación respaldatoria fiscal, existiendo también la limitación de gastos electorales, donde se sufrirán penalidades en caso de incumplimiento de lo previsto en la Ley $N^{\circ} 9.504 / 1997$ de la siguiente manera:

Art.18-B. El incumplimiento de los límites de gastos fijados para cada campaña resultará en el pago de una multa en valor equivalente al $100 \%$ (cien por ciento) de la cantidad que sobrepase el límite establecido sin perjuicio del cálculo de la ocurrencia del abuso del poder económico (Ley 9.504, 1997, art.18).

De acuerdo con el artículo $32^{\circ}$ de la Ley № 9.096/1995, los partidos políticos están obligados a enviar, anualmente, a la Justicia Electoral, el balance contable del ejercicio finalizado hasta el día 30 de abril del año siguiente. El capítulo V de la Resolución TS N²3.546/2017 determina algunas reglas para los órganos partidarios, por ejemplo: utilizar el registro contable digital.

Art.26. El registro contable digital comprende la versión digital:

I - del Libro Diario y sus auxiliares; y

II - del Libro Mayor y sus auxiliares;

$1^{\circ}$ La registración contable digital deberá observar lo dispuesto en esta Resolución y en los actos expedidos por la Receita Federal Do Brasil y por el Consejo Federal de Contabilidad. (Resolución TSE, 23.546, 2017, art.26).

\footnotetext{
"Visión de Futuro" Año 17, Volumen N²4 N², Julio - Diciembre 2020 - Pág. 1 - 19

URL de la Revista: http://visiondefuturo.fce.unam.edu.ar/index.php/visiondefuturo/index

URL del Documento: https://visiondefuturo.fce.unam.edu.ar/index.php/visiondefuturo/issue/view/18

ISSN 1668 - 8708 - Versión en Línea

E-mail: revistacientifica@fce.unam.edu.ar
} 
Esta evidencia exigida es importante para proporcionar resultados con el máximo de transparencia, de comprensión y legalidad de los datos recabados. En las entidades del Tercer Sector, específicamente los partidos políticos, es válida para comprender la situación financiera y económica de las organizaciones que utilizan y gestionan los recursos públicos, esto es, recursos de toda la sociedad que para debidamente sus impuestos y no desea ver un despilfarro innecesario o ilegal.

Para mejorar la transparencia de los partidos políticos, sería interesante exigir una contabilidad más detallada, órganos de control más eficientes, informes de mejor calidad y el fortalecimiento de las leyes vigentes, pues la contabilidad y la rendición de cuentas son medidas preventivas y herramientas de control para combatir la ausencia de claridad en la política. La operatividad de las cuentas partidarias es enemiga del desarrollo de un entorno político saludable y puede afectar la credibilidad, las afiliaciones a los partidos y las donaciones de terceros, alcanzando a los ingresos y dificultando su mantenimiento.

La idea de que la Ciencia Contable solo sea importante para las entidades con fines de lucro es bastante desfasada. Esta ciencia social aplicada no solamente es obligatoria, dada una imposición legal, sino que se trata de una herramienta necesaria para la gestión, que ayuda a los gestores y usuarios en la toma de decisiones y, en el caso de los partidos políticos, promueve asimismo la transparencia para los dueños de los recursos que estas entidades gestionan: la sociedad en general.

Dado el referencial presentado, se investigan las relaciones entre personas, cuentas y partidos políticos considerados irregulares bajo el punto de vista del análisis de la transparencia de los fondos partidarios, así como la relación de los grupos de partidos que presentan un conjunto de estados contables en relación a los demás.

\section{Metodología, presentación y análisis de datos}

Este trabajo, de acuerdo con su objetivo, fue clasificado como una investigación explicativa por el hecho de poseer como preocupación central identificar los factores que determinan o que contribuyen con la ocurrencia de determinado fenómeno, de acuerdo con Gil (1991). Según Lakatos y Marconi (2011), la investigación explicativa registra hechos, los analiza, los interpreta e identifica sus causas. Esta práctica tiene como fin ampliar las generalizaciones, definir leyes más amplias, estructurar y definir modelos teóricos, relacionar hipótesis con una visión más unitaria del universo o ámbito productivo en general y generar hipótesis o ideas mediante la fuerza de la deducción lógica.

\footnotetext{
"Visión de Futuro" Año 17, Volumen No 24 N², Julio - Diciembre 2020 - Pág. 1 - 19

URL de la Revista: http://visiondefuturo.fce.unam.edu.ar/index.php/visiondefuturo/index

URL del Documento: https://visiondefuturo.fce.unam.edu.ar/index.php/visiondefuturo/issue/view/18

ISSN 1668 - 8708 - Versión en Línea

E-mail: revistacientifica@fce.unam.edu.ar
} 
Asimismo, se hace necesario el uso de la investigación bibliográfica. Según Gil (1991), la investigación bibliográfica se desarrolla a partir de un material ya elaborado, constituido principalmente por libros y artículos científicos. Se utilizó para la realización de este trabajo el análisis documental, bibliográfico y estadístico, con la ayuda de dos softwares SPSS, PAST y EXCEL-XLSAT, teniendo como hipótesis y modelos lo expuesto a continuación:

$\mathrm{H}_{1}$ : Existe una correlación entre los valores transferidos por el TSE y el № de cuentas irregulares en los estados;

$\mathrm{H}_{2}$ : Existe una correlación entre los valores transferidos por el TSE y el № de personas con cuentas irregulares en los estados;

$\mathrm{H}_{3}$ : Existe una relación entre grupos de partidos políticos que presentan una mayor cantidad de estados contables con la transferencia de fondos partidarios a los referidos grupos.

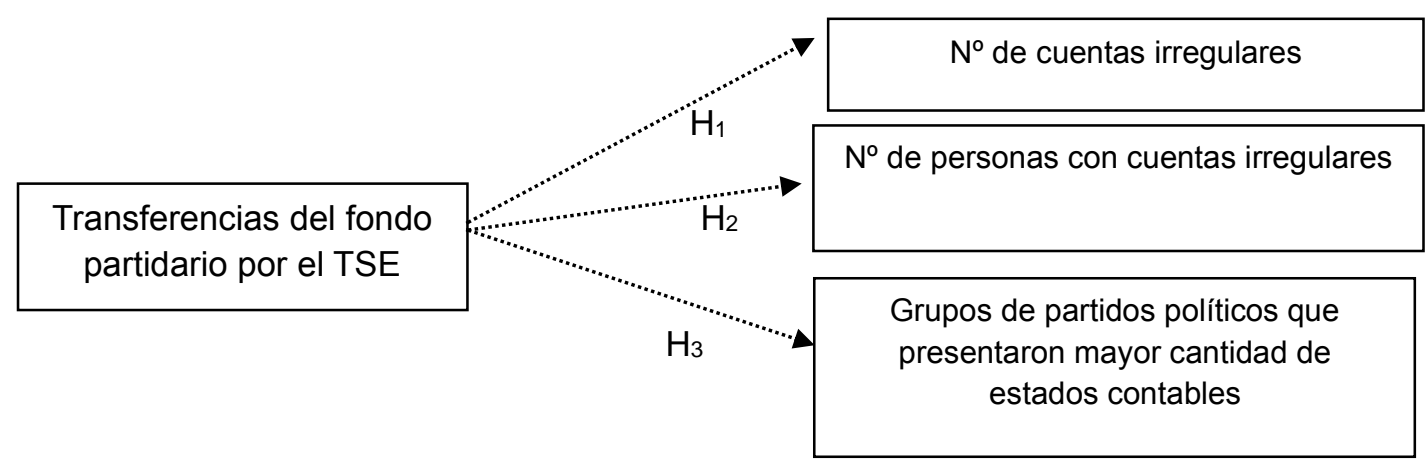

Figura $\mathrm{N}^{\circ}$ 1. Hipótesis y modelos para correlación

Fuente: Elaboración Propia

A continuación, se analizó la situación de las cuentas irregulares observando todas las unidades federales, considerando como variables el número de cuentas irregulares, el número de personas con cuentas juzgadas irregulares y el valor transferido al fondo partidario, de acuerdo con los datos del TSE y TCU, de acuerdo con lo expuesto en la tabla 1:

Tabla $\mathrm{N}^{\circ}$ 1. Cuentas irregulares de acuerdo con los datos del TSE y TCU

\begin{tabular}{|c|c|c|c|c|c|c|c|}
\hline \multicolumn{7}{|c|}{ LISTA DE CUENTAS JUZGADAS IRREGULARES - DISTRIBUCIÓN POR UF } \\
\hline ESTADO & $\begin{array}{c}\text { NÚMERO DE } \\
\text { CUENTAS }\end{array}$ & $\%$ & $\begin{array}{c}\text { NÚMERO DE } \\
\text { PERSONAS }\end{array}$ & $\%$ & $\begin{array}{c}\text { VALOR TRANSFERIDO AL } \\
\text { FONDO PARTIDARIO - TSE }\end{array}$ & $\%$ \\
\hline AC & 198 & 1,62 & 113 & 1,43 & & $4.140 .899,69$ & 2,24 \\
\hline AL & 222 & 1,82 & 135 & 1,71 & $3.641 .135,51$ & 1,97 \\
\hline AM & 519 & 4,25 & 286 & 3,62 & $9.112 .607,26$ & 4,93 \\
\hline AP & 191 & 1,56 & 136 & 1,72 & $3.463 .644,29$ & 1,87 \\
\hline BA & 761 & 6,23 & 513 & 6,49 & $11.564 .528,58$ & 6,25 \\
\hline CE & 630 & 5,16 & 387 & 4,90 & $6.126 .625,01$ & 3,31 \\
\hline DF & 481 & 3,94 & 327 & 4,14 & & $5.916 .397,45$ & 3,20 \\
\hline ES & 165 & 1,35 & 129 & 1,63 & & 2,20 \\
\hline
\end{tabular}

\footnotetext{
"Visión de Futuro" Año 17, Volumen No 24 N², Julio - Diciembre 2020 - Pág. 1 - 19

URL de la Revista: http://visiondefuturo.fce.unam.edu.ar/index.php/visiondefuturo/index

URL del Documento: https://visiondefuturo.fce.unam.edu.ar/index.php/visiondefuturo/issue/view/18

ISSN 1668 - 8708 - Versión en Línea

E-mail: revistacientifica@fce.unam.edu.ar
} 


\begin{tabular}{|c|c|c|c|c|c|c|}
\hline GO & 315 & 2,58 & 237 & 3,00 & $5.973 .989,78$ & 3,23 \\
\hline MA & 1453 & 11,90 & 705 & 8,92 & $4.665 .352,18$ & 2,52 \\
\hline$M G$ & 701 & 5,74 & 511 & 6,47 & $15.305 .013,36$ & 8,27 \\
\hline MS & 149 & 1,22 & 96 & 1,22 & $3.119 .252,41$ & 1,69 \\
\hline MT & 357 & 2,92 & 234 & 2,96 & $3.812 .032,26$ & 2,06 \\
\hline PA & 760 & 6,22 & 417 & 5,28 & $6.436 .273,08$ & 3,48 \\
\hline PB & 523 & 4,28 & 321 & 4,06 & $5.080 .742,56$ & 2,75 \\
\hline$P E$ & 566 & 4,63 & 375 & 4,75 & $8.601 .139,61$ & 4,65 \\
\hline $\mathrm{PI}$ & 360 & 2,95 & 244 & 3,09 & $5.352 .554,50$ & 2,89 \\
\hline PR & 337 & 2,76 & 255 & 3,23 & $9.083 .371,78$ & 4,91 \\
\hline RJ & 992 & 8,12 & 672 & 8,51 & $10.339 .051,49$ & 5,59 \\
\hline $\mathrm{RN}$ & 302 & 2,47 & 206 & 2,61 & $4.930 .426,86$ & 2,67 \\
\hline $\mathrm{RO}$ & 224 & 1,83 & 162 & 2,05 & $3.664 .780,41$ & 1,98 \\
\hline $\mathrm{RR}$ & 259 & 2,12 & 114 & 1,44 & $2.872 .526,56$ & 1,55 \\
\hline RS & 270 & 2,21 & 193 & 2,44 & $7.157 .059,46$ & 3,87 \\
\hline SC & 158 & 1,29 & 134 & 1,70 & $6.182 .870,55$ & 3,34 \\
\hline SE & 260 & 2,13 & 200 & 2,53 & $3.993 .051,93$ & 2,16 \\
\hline SP & 810 & 6,63 & 614 & 7,77 & $25.607 .782,25$ & 13,84 \\
\hline TO & 252 & 2,06 & 185 & 2,34 & $4.765 .947,88$ & 2,58 \\
\hline TOTAIS & 12.215 & $\begin{array}{c}100,0 \\
0\end{array}$ & 7.901 & $\begin{array}{c}100,0 \\
0\end{array}$ & $184.980 .637,30$ & 100,00 \\
\hline
\end{tabular}

Fuente: Elaboración Propia a partir de datos del TSE y TCU (2018)

Consultando la base de datos del TSE, se verifica un aumento de las cuentas irregulares que deben ser observadas en relación a los problemas relevados en el referencial de este trabajo. Se percibe una evolución de acuerdo con el grafico presentado a continuación:

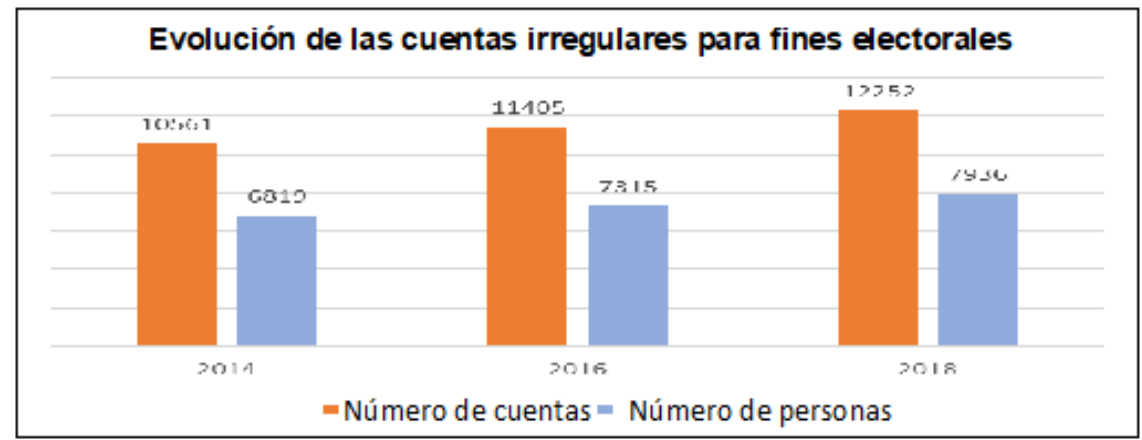

Gráfico $N^{\circ} 1$. Evolución de las cuentas irregulares para fines electorales Fuente: Elaboración Propia a partir de datos del TSE (2018)

Luego de la presentación de la tabla, se realizaron pruebas estadísticas para verificar el coeficiente de determinación y el valor $p$ mediante la regresión entre las variables y para el tratamiento de los datos, el análisis estadístico, la construcción de tablas y gráficos se utilizó el software EXCEL con el suplemento XLSAT, de acuerdo a lo que se demuestra a continuación:

\footnotetext{
"Visión de Futuro" Año 17, Volumen No 24 N², Julio - Diciembre 2020 - Pág. 1 - 19

URL de la Revista: http://visiondefuturo.fce.unam.edu.ar/index.php/visiondefuturo/index

URL del Documento: https://visiondefuturo.fce.unam.edu.ar/index.php/visiondefuturo/issue/view/18

ISSN 1668 - 8708 - Versión en Línea

E-mail: revistacientifica@fce.unam.edu.ar
} 
Tabla $N^{\circ}$ 2. Análisis Estadísticas de conteo x personas

\begin{tabular}{|c|c|c|c|c|c|c|c|c|}
\hline & \multicolumn{7}{|c|}{ Estatística de regressão } \\
\hline R múltiplo & 0,851 & & & & & & & \\
\hline R-Quadrado & 0,725 & & & & & & & \\
\hline R-quadrado ajus & 5 0,702 & & & & & & & \\
\hline Erro padrão & 1,401 & & & & & & & \\
\hline Observações & 27 & & & & & & & \\
\hline \multicolumn{9}{|l|}{ ANOVA } \\
\hline & $g l$ & $S Q$ & $M Q$ & $F$ & Fde significação & & & \\
\hline Regressão & 2 & 124,1795254 & 62,089763 & 31,64217712 & 0,00000019 & & & \\
\hline Resíduo & 24 & 47,09392465 & 1,9622469 & & & & & \\
\hline \multirow[t]{2}{*}{ Total } & 26 & 171,27345 & & & & & & \\
\hline & oeficients & Erro padrão & Stat $t$ & valor- $P$ & 95\% inferiores & 95\% superiores & Inferior 95,0\% & Superior $95,0 \%$ \\
\hline Interseção & 0,426 & 0,53842302 & 0,7909434 & 0,436723993 & $-0,685388384$ & 1,537112608 & $-0,685388384$ & 1,537112608 \\
\hline CONTAS (\%) & $-2,016$ & 0,386031085 & $-5,221236$ & 0,0000238 & $-2,812288352$ & $-1,218830351$ & $-2,812288352$ & $-1,218830351$ \\
\hline PESSOAS (\%) & 2,901 & 0,432402704 & 6,7080445 & 0,0000006 & 2,008141264 & 3,793011899 & 2,008141264 & 3,793011899 \\
\hline
\end{tabular}

Fuente: Elaboración Propia

De acuerdo con lo expuesto precedentemente, se verifica que el $72,50 \%$ de las variables cantidad de cuentas y personas con cuentas irregulares son explicadas mediante la variable traspaso del TSE a cada estado, así como la prueba muestra el coeficiente f de significación de 0,00000019 y por los valores bajos de $p$ de las variables de 0,05 . A continuación, se procedió

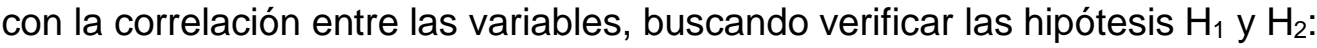

$\mathrm{H}_{1}$ : Existe una correlación entre los valores transferidos por el TSE y el № de cuentas irregulares en los estados;

$\mathrm{H}_{2}$ : Existe una correlación entre los valores transferidos por el TSE y el № de personas con cuentas irregulares en los estados:

Tabla $N^{\circ}$ 3. Matriz de correlación (Pearson)

\begin{tabular}{|c|c|c|c|}
\hline Variables & Transferencias (\%) & Cuentas (\%) & Personas (\%) \\
\hline TRANFERENCIAS (\%) & 1 & 0,458 & 0,642 \\
\hline CUENTAS (\%) & 0,458 & 1 & 0,959 \\
\hline PERSONAS (\%) & 0,642 & 0,959 & 1 \\
\hline
\end{tabular}

Fuente: Elaboración Propia

Luego del análisis estadístico es posible presentar el modelo a continuación:

\section{TRANSF.TSE $=0$,425862112148234 $-2,0155593516345^{\star}$ CONTIR $+2,90057658135448 *$ PESCONTIRREG}

El gráfico mostrado a continuación presenta una buena distribución de los datos y de los residuos, con un buen ajuste de la recta al conjunto de los datos, pues los mismos tienden a fluctuar hacia ambos lados sin, necesariamente, seguir un modelo de comportamiento, que confirma $\mathrm{H}_{1}$ y $\mathrm{H}_{2}$.

\footnotetext{
“Visión de Futuro" Año 17, Volumen No 24 N², Julio - Diciembre 2020 - Pág. 1 - 19

URL de la Revista: http://visiondefuturo.fce.unam.edu.ar/index.php/visiondefuturo/index

URL del Documento: https://visiondefuturo.fce.unam.edu.ar/index.php/visiondefuturo/issue/view/18

ISSN 1668 - 8708 - Versión en Línea

E-mail: revistacientifica@fce.unam.edu.ar
} 


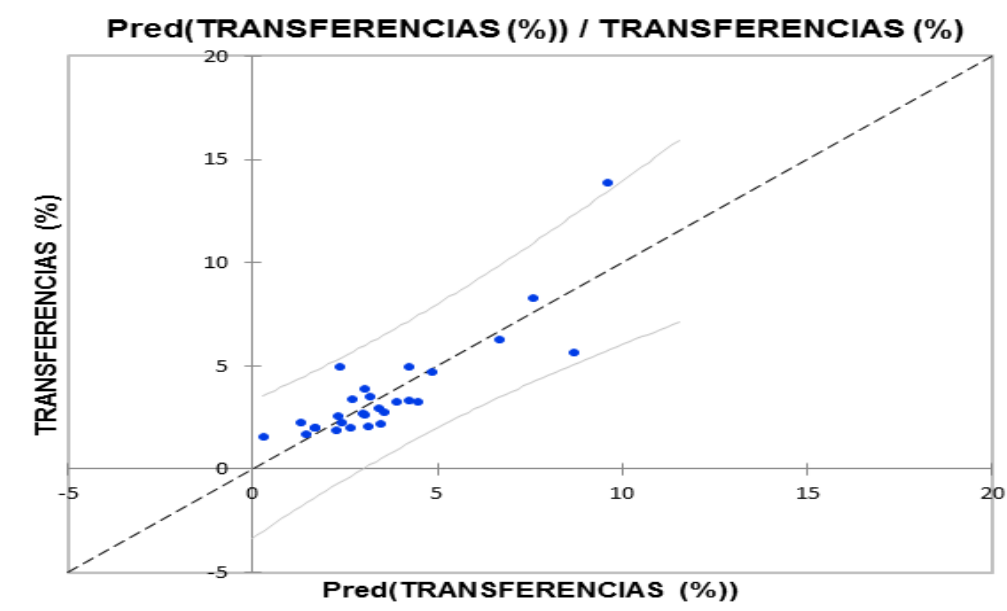

Gráfico $\mathrm{N}^{\circ}$ 2. Distribución de los coeficientes y análisis de los residuos de la Transferencia Fuente: Elaboración propia a partir de datos del TSE (2018)

A continuación, se observa la distribución de las transferencias del fondo partidario hacia todos los partidos políticos, de acuerdo con la legislación, así como el traspaso de los valores transferidos a los directorios regionales, inclusive con partidos que no traspasan ningún valor a su directorio regional, lo que refuerza la necesidad de una contabilidad efectiva de los valores recibidos y los gastos, así como la variación patrimonial entre coaliciones y entre los directorios nacionales y regionales para identificar posibles inexactitudes con la legislación y, consecuentemente, reducir la cantidad de cuentas irregulares.

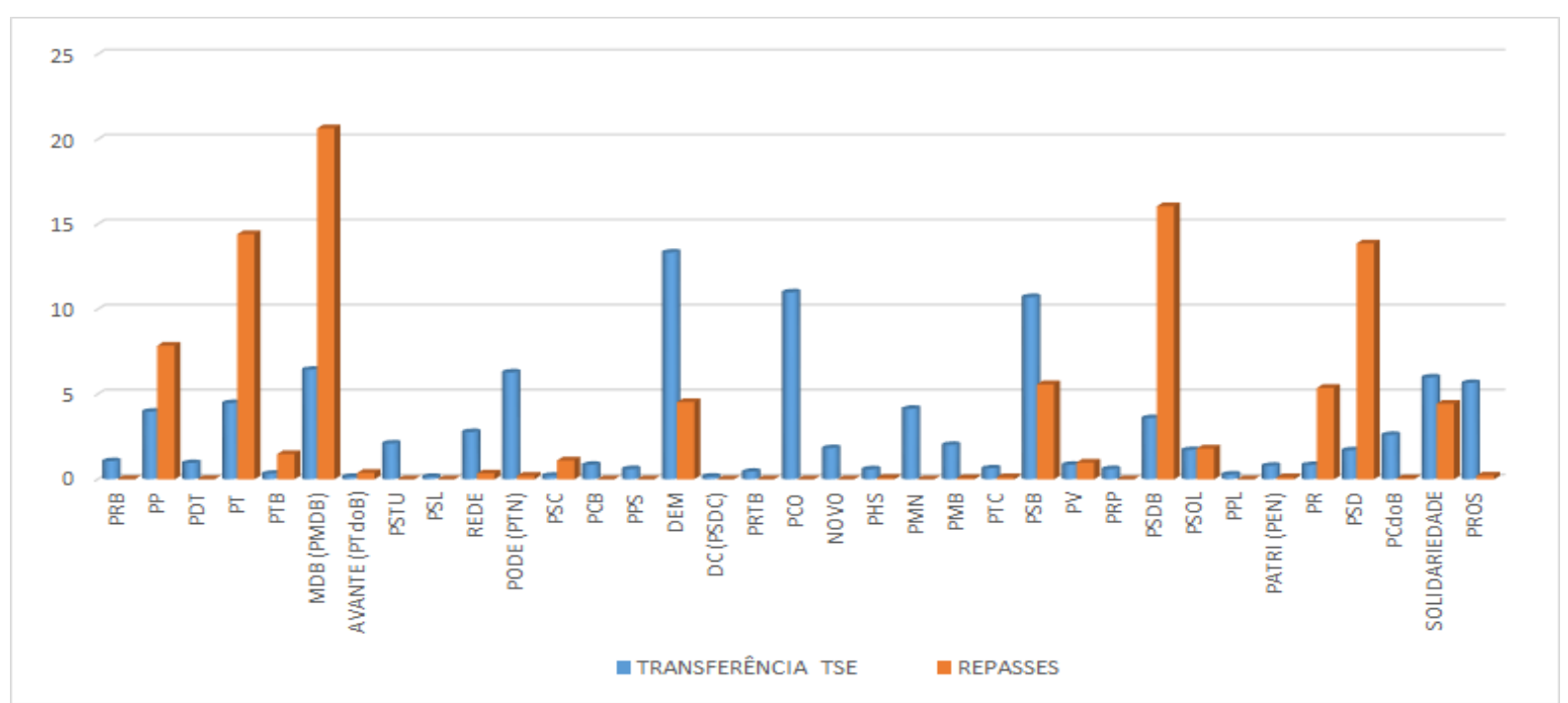

Gráfico $N^{\circ}$ 3. Transferencias del Fondo Partidario a los partidos y de estos a los directorios Fuente: Elaboración Propia a partir de datos del TSE (2018)

A partir de los datos relevados sobre las transferencias a los partidos políticos, se recabó información en los sitios de internet de los mismos y del TSE sobre los estados contables,

\footnotetext{
"Visión de Futuro" Año 17, Volumen No 24 N², Julio - Diciembre 2020 - Pág. 1 - 19

URL de la Revista: http://visiondefuturo.fce.unam.edu.ar/index.php/visiondefuturo/index

URL del Documento: https://visiondefuturo.fce.unam.edu.ar/index.php/visiondefuturo/issue/view/18

ISSN 1668 - 8708 - Versión en Línea

E-mail: revistacientifica@fce.unam.edu.ar
} 
clasificando por grupo de partidos que poseían similitudes en la cantidad de documentación contables presentada, de acuerdo con la tabla a continuación:

Tabla $N^{\circ} 4$. Distribución por grupos de partidos $x$ cantidad de Estados Contables

\begin{tabular}{|l|c|c|c|}
\hline \multicolumn{1}{|c|}{ PARTIDOS POLÍTICOS } & GRUPOS & $\begin{array}{c}\text { GRUPOS P/ } \\
\text { CANTIDAD DE } \\
\text { ESTADOS } \\
\text { CONTABLES }\end{array}$ & $\begin{array}{c}\text { TRANSFERENCIAS } \\
\text { FONDO TSE POR } \\
\text { GRUPOS }\end{array}$ \\
\hline $\begin{array}{l}\text { PSB / PT / PMN / PTB / PSOL / PTC / } \\
\text { PRP / PHS / PTB / PSC }\end{array}$ & $\begin{array}{c}\text { A - TODOS LOS } \\
\text { ESTADOS CONTABLES }\end{array}$ & 10 & $173.120 .837,69$ \\
\hline $\begin{array}{l}\text { PODEMOS / PP / PRB / PSD / } \\
\text { SOLIDARIEDADE / REDE / PSTU }\end{array}$ & $\begin{array}{c}\text { B - CUATRO ESTADOS } \\
\text { CONTABLES }\end{array}$ & 7 & $177.681 .027,37$ \\
\hline PC do B / NOVO / PRTB & $\begin{array}{c}\text { C - TRES ESTADOS } \\
\text { CONTABLES }\end{array}$ & 3 & $36.136 .936,85$ \\
\hline DEM / MDB / PMB / PPL / DC & $\begin{array}{c}\text { D - DOS ESTADOS } \\
\text { CONTABLES }\end{array}$ & 5 & $164.297 .653,67$ \\
\hline PSDB / PDT / PV / PSL & $\begin{array}{c}\text { E - UN ESTADO } \\
\text { CONTABLE }\end{array}$ & 4 & $104.029 .030,72$ \\
\hline PCO / PCB / PR / PATRI / PPS & $\begin{array}{c}\text { F - NINGÚN ESTADO } \\
\text { CONTABLE }\end{array}$ & 5 & $41.005 .621,59$ \\
\hline
\end{tabular}

Fuente: Elaboración Propia a partir de datos del TSE y partidos (2018)

Para analizar estos datos, basados en la referencia de este estudio, se formuló la hipótesis $\mathrm{H}_{3}$ : Existe una relación entre los grupos de partidos políticos que presentan una mayor cantidad de estados contables con las transferencias de fondos partidarios a los referidos grupos.

Para aplicar la estadística adecuada para presentar el modelo y probar la hipótesis, se procedió con la prueba de normalidad y a partir de los resultados, se optó por los test paramétricos:

Tabla $\mathrm{N}^{\circ}$ 5. Test de normalidad para grupos $\mathrm{x}$ transferencias

\begin{tabular}{|l|rr|}
\hline & $\begin{array}{c}\text { Grupos } \mathrm{p} / \text { cantidad } \\
\text { de estados contables }\end{array}$ & $\begin{array}{c}\text { Transferencia Fondo } \\
\text { Partidario TSE }\end{array}$ \\
\hline $\mathrm{N}$ & 6 & 6 \\
\hline Shapiro-Wilk W & 0,9076 & 0,8261 \\
\hline $\mathrm{p}$ (normal) & 0,4207 & 0,0996 \\
\hline Anderson-Darling A & 0,3476 & 0,4917 \\
\hline $\mathrm{p}$ (normal) & 0,3384 & 0,1286 \\
\hline $\mathrm{p}$ (Monte Carlo) & 0,3752 & 0,1439 \\
\hline Jarque-Bera JB & 0,6139 & 0,7935 \\
\hline $\mathrm{p}$ (normal) & 0,7357 & 0,6725 \\
\hline $\mathrm{p}$ (Monte Carlo) & 0,4220 & 0,2226 \\
\hline
\end{tabular}

Fuente: Elaboración Propia con la utilización del PAST

A continuación, se presenta el informe con los resultados del análisis estadístico ANOVA, resaltando los valores de $R^{2}$ de 0,713 y $p$ de 0,034

\footnotetext{
"Visión de Futuro" Año 17, Volumen No 24 N², Julio - Diciembre 2020 - Pág. 1 - 19

URL de la Revista: http://visiondefuturo.fce.unam.edu.ar/index.php/visiondefuturo/index

URL del Documento: https://visiondefuturo.fce.unam.edu.ar/index.php/visiondefuturo/issue/view/18

ISSN 1668 - 8708 - Versión en Línea

E-mail: revistacientifica@fce.unam.edu.ar
} 
Tabla №6. Estadística de regresión

\begin{tabular}{|l|r|}
\hline \multicolumn{2}{|c|}{ Estadística de regresión } \\
\hline R múltiple & 0,84448935 \\
\hline R-Cuadrado & 0,71316226 \\
\hline R-Cuadrado ajustado & 0,64145283 \\
\hline Error estándar & 39306741,4 \\
\hline Observaciones & 6 \\
\hline
\end{tabular}

\begin{tabular}{|c|c|c|c|c|c|}
\hline \multicolumn{6}{|l|}{ ANOVA } \\
\hline & $\mathrm{gl}$ & $S Q$ & $\mathrm{MQ}$ & $\mathrm{F}$ & F de significación \\
\hline Regresión & 1 & $1,53655 \mathrm{E}+16$ & $1,54 \mathrm{E}+16$ & 9,945167 & 0,034394942 \\
\hline Residuo & 4 & $6,18008 \mathrm{E}+15$ & $1,55 \mathrm{E}+15$ & & \\
\hline Total & 5 & $2,15456 \mathrm{E}+16$ & & & \\
\hline
\end{tabular}

\begin{tabular}{|l|l|l|l|l|l|l|}
\hline & Coeficientes & Error estándar & Stat t & valor-P & 95\% inferiores & 95\% superiores \\
\hline Intersección & -18310003 & 45525681,68 & 0,40219064 & 0,708109 & -144709559 & 108089553,1 \\
\hline $\begin{array}{l}\text { Grupos p/ } \\
\text { cantidad estados }\end{array}$ & 23709739 & 7518318,888 & 3,153595816 & 0,034395 & 2835539,313 & 44583938,66 \\
\hline
\end{tabular}

Fuente: Elaboración Propia

Ecuación del modelo:

Transferencia Fondo TSE $=-18310002,9464634+23709738,9873171^{*}$ Grupos $\mathrm{p} /$ cantidad Estados Contables

Se puede, de esta manera, confirmar la $\mathrm{H}_{3}$ : Existe una relación entre los grupos de partidos políticos que presentan una mayor cantidad de estados contables con las transferencias de fondos partidarios a los referidos grupos, pues se interpreta que, dado el $R^{2}$, el $71,32 \%$ de la variabilidad de la Transferencia de fondos por parte del TSE, que es la variable independiente, calculado en la tabla de ANOVA, y dado el nivel de significancia del $5 \%$, o sea, de 0,034 , la información proporcionada por las variables explicativas fue significativamente mejor que una media básica, de acuerdo con lo observado en la grafico a continuación:

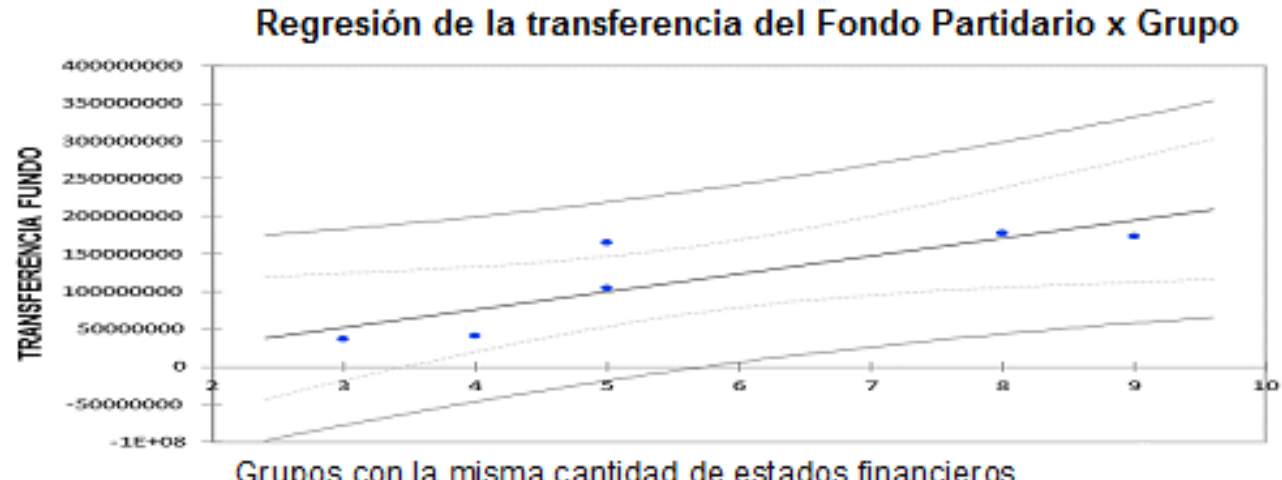

Grupos con la misma cantidad de estados financieros

Gráfico 4. Regresión de la Transferencias del Fondo Partidario x Grupo

Fuente: Elaboración Propia a partir de datos de la investigación (2018)

\footnotetext{
"Visión de Futuro" Año 17, Volumen N²4 N², Julio - Diciembre 2020 - Pág. 1 - 19

URL de la Revista: http://visiondefuturo.fce.unam.edu.ar/index.php/visiondefuturo/index

URL del Documento: https://visiondefuturo.fce.unam.edu.ar/index.php/visiondefuturo/issue/view/18

ISSN 1668 - 8708 - Versión en Línea

E-mail: revistacientifica@fce.unam.edu.ar
} 
Considerando todo lo expuesto en esta investigación, se verifica la necesidad de un control efectivo en el traspaso de los recursos, con vistas a obtener más información en la rendición de cuentas de los partidos políticos que siguen a raja tabla la exigencia de la Ley № 9.096/95, reglamentada por la Resolución № 23.546/2017, en lo que concierne a la presentación de Estados Contables ante la Justicia Electoral.

"Art. $4^{\circ}$ Los partidos políticos, en todos los niveles de dirección, deben:

$[.$.

V - remitir a la Justicia Electoral, en los plazos establecidos en esta resolución:

a) el Balance Patrimonial y el Estado de Resultados del Ejercicio, para su publicación en la forma establecida por la Secretaria Judicial de los tribunales; $y$

b) la rendición de cuentas anual". (Resolución 23.546, 2017, art 4ª̣).

El Consejo Federal de Contabilidad - CFC, a su vez, a través de la ITG 2002 - R1 establece criterios y procedimientos específicos al respecto de la elaboración de los Estados Contables para las entidades del tercer sector, donde se encajan los partidos políticos, e incluye tres piezas mas no abordadas por la Resolución № 23.546/2017.

Conociendo la competencia del CFC de abordar y reglamentar la contabilidad y sus profesionales, se entiende que el relevamiento de estas tres piezas omitidas por la legislación acarrea más transparencia a los hechos ocurridos dentro de los partidos y, consecuentemente, propicia a la Justicia Electoral para que prevenga casos de corrupción en el país.

\section{CONCLUSIÓN}

La contabilidad, como instrumento de ayuda a la gestión y principal fuente de información para los usuarios, debe ser más utilizada por los órganos fiscalizadores, sobre todo la Justicia Electoral, tomando en cuenta la posibilidad de combatir y prevenir la corrupción mediante un análisis minucioso de todos los estados contables referidos en la ITG 2002 (R1).

Para la rendición de cuentas de los partidos políticos, se requiere un mínimo de información, al mencionar solamente dos estados contables establecidos por la legislación vigente, el de situación contable-financiera a lo largo del año calendario.

La presente investigación demostró, cuantitativamente, la fragilidad de las cuentas partidarias, teniendo en cuenta el crecimiento de $16 \%$ de aquellas consideradas irregulares, en un orden de magnitud de decenas de miles de cuentas, entre 2014 y 2018 . Esta anormalidad es influida fuertemente por la disparidad entre la legislación vigente, en lo que se refiere a las finanzas y la contabilidad de los partidos, y las normativas contables, editadas por un órgano con un amplio dominio en este campo del saber: Consejo Federal de Contabilidad.

De esta manera, se considera alcanzado el objetivo general del estudio presentado, es decir, verificar la necesidad de elaboración de estados contables para la promoción de la

\footnotetext{
"Visión de Futuro" Año 17, Volumen No 24 N², Julio - Diciembre 2020 - Pág. 1 - 19

URL de la Revista: http://visiondefuturo.fce.unam.edu.ar/index.php/visiondefuturo/index

URL del Documento: https://visiondefuturo.fce.unam.edu.ar/index.php/visiondefuturo/issue/view/18

ISSN 1668 - 8708 - Versión en Línea

E-mail: revistacientifica@fce.unam.edu.ar
} 
transparencia, ya que las dos piezas exigidas por la Resolución № 23.546/2017 deben ser complementadas con otras dos piezas establecidas en la ITG 2002 - R1/

En línea con las consideraciones supra mencionadas, se resalta, ahora en términos técnicos, la existencia de una correlación positiva moderada entre los valores transferidos por el TSE y el número de cuenta irregulares en los estados, así como también existe una correlación positiva substancial entre los valores transferidos por el TSE y el número de personas con cuentas irregulares en los estados.

En este sentido, se percibe la necesidad de utilización de una práctica contable nivelada, en su totalidad, con las normas e instrucciones del CFC. Esta autarquía, con toda su organización y expertos en el ramo, podría dialogar con la Justicia Electoral y unir esfuerzos para prevenir y combatir la baja calidad en el ejercicio de la accountability, asegurando la regularidad de las cuentas partidarias y promoviendo la expansión de un entorno libre de fraudes y enfocada en satisfacer las necesidades de la sociedad. El gran avance en el ámbito político-partidario sería una fiscalización en los moldes del mercado de valores mobiliarios, salvo las debidas proporciones. O sea, el CFC actuaria libremente como la Comisión de Valores Mobiliarios CVM, presionando a los partidos para que observen las buenas prácticas contables y facilitar el acceso público a la información financiera además de amenizar la actuación de la Justicia Electoral en lo que se refiere a la protección de los recursos públicos.

Asimismo, se observa la importancia del papel de la contabilidad en las transferencias de recursos del fondo partidario del TSE a los partidos, y de estos a sus directorios regionales, pues, es posible notar la concentración de estos recursos por parte de algunos partidos, y otros que traspasan sin la información calificada de estos eventos, lo que tampoco permite el seguimiento por parte de la justicia y de los órganos de control y seguimiento, tales como los tribunales de cuentas y ministerios públicos.

Al respecto del objetivo específico de comprender el impacto de la elaboración parcial de los estados contables en lo que se refiere a las cuentas juzgadas irregulares y la transferencia de recursos vía fondo partidario, se considera igualmente alcanzado durante la investigación, considerando la constatación de una correlación entre los valores transferidos por el TSE y el número de cuentas irregulares en los estados; una correlación entre los valores transferidos por el TSE y el número de personas con cuentas irregulares en los estados; y, también, una relación entre los grupos de partidos políticos que presentan una mayor cantidad de estados contables con las transferencias de fondos partidarios a los referidos grupos.

Esta investigación se limitó, mediante un enfoque cualitativo y cuantitativo, a la confrontación entre la difusión de los Estados Contables, determinada por la ley, que, de hecho,

\footnotetext{
"Visión de Futuro" Año 17, Volumen N² 24 N², Julio - Diciembre 2020 - Pág. 1 - 19

URL de la Revista: http://visiondefuturo.fce.unam.edu.ar/index.php/visiondefuturo/index

URL del Documento: https://visiondefuturo.fce.unam.edu.ar/index.php/visiondefuturo/issue/view/18

ISSN 1668 - 8708 - Versión en Línea

E-mail: revistacientifica@fce.unam.edu.ar
} 
establece obligaciones y sanciones para el incumplimiento de las reglas y la difusión determinada por el texto técnico-normativo del área contable, el cual posee un sesgo instructivo y esclarecedor. De esta manera, se constata que la laguna existente entre las dos normativas, legal y técnica, permita la ejecución de rendiciones de chuetas dudosas y de difícil fiscalización por parte de la Justicia Electoral, teniendo en cuenta la ausencia de sanciones y continuidad en la transferencia de recursos de aquellos partidos con pocos estados contables presentados. No obstante, para investigaciones futuras, se estimulan estudios más profundos y representativos de la situación contable-financiera de los partidos políticos, de manera individual, dirigida hacia los criterios de evidencia propuestos por las normativas contables.

\section{REFERENCIAS}

Brasil, Ley № 9.096. Dispõe sobre partidos políticos, regulamenta os arts. 17 e 14, par. $3^{\circ}$, inciso $\mathrm{V}$, da construção Federal, 19 de setembro de 1995 Disponible en: http://www.planalto.gov.br/ccivil 03/LEIS/L9096.htm, Acceso el: 28 ago. 2018.

Conselho Federal De Contabilidade. (2015). ITG 2002 (R1). Altera a ITG 2002 que trata de entidades sem finalidade de lucros. Brasília. Disponible en: http://www1.cfc.org.br/sisweb/SRE/docs/ITG2002(R1).pdf Acceso el: 25 ago. 2018.

Ferrari, Ed. Luiz. (2008), Contabilidade geral: provas e concursos. 8. ed. Rio de Janeiro: Elsevier. Gil, Antonio C. (1991), Como elaborar projetos de pesquisa. $3^{\circ}$ Ed. São Paulo, Atlas. Disponible en: $\quad$ http://www.ie.ufri.br/intranet/ie/userintranet/hpp/arquivos/031120162924

AntonioCarlosGil ComoElaborarProjetosdePesquisa EditoraAtlasCopia.pdf Acceso el: 26 ago. 2018.

ludícibus, S. et al. (2010), Contabilidade introdutória. - 11. ed. - São Paulo: Atlas.

Lakatos, E. M.; Marconi, M. A. (2011). Metodologia científica, 6 Ed. Atlas.

Melo, Josenilton Balbino de. Terceiro setor: contabilidade aplicada aos partidos políticos. Rondonópolis: UFMT, 2017. Monografia (Graduação em Ciências Contábeis), Instituto de Ciências Humanas e Sociais, Universidade Federal de Mato Grosso, 2017.

Milani filho, Marco Antonio Figueiredo. (2009), Eficiência produtiva no terceiro setor: um estudo comparativo de desempenho entre organizações filantrópicas asilare. Departamento de Contabilidade e Atuária/USP: São Paulo. Disponible en: http://www.teses.usp.br/teses/disponiveis/12/12136/tde-14102009-124436/pt-br.php Acceso el: 15 dez. 2018.

Oliveira, Irani Maria da Silva. (2009), Uma investigação sobre a prestação de contas das entidades do Terceiro Setor Brasileiro. Recife: UFPE. Dissertação (Mestrado em Ciências "Visión de Futuro" Año 17, Volumen No 24 N², Julio - Diciembre 2020 - Pág. 1 - 19

URL de la Revista: http://visiondefuturo.fce.unam.edu.ar/index.php/visiondefuturo/index

URL del Documento: https://visiondefuturo.fce.unam.edu.ar/index.php/visiondefuturo/issue/view/18

ISSN 1668 - 8708 - Versión en Línea

E-mail: revistacientifica@fce.unam.edu.ar 
Contábeis), Departamento de Ciências Contábeis, Universidade Federal de Pernambuco, 2009.

Pontes, Carla Sena. (2008), A atuação da Justiça Eleitoral na fiscalização das contas dos candidatos e partidos políticos. Rio de Janeiro: PUC-Rio. Dissertação (Mestrado em Direito), Departamento de Direito, Pontifícia Universidade Católica do Rio de Janeiro, 2008. Silva, De Plácido e. (1999), Vocabulário jurídico. 15. ed. Rio de Janeiro: Forense.

Tribunal Superior Eleitoral. Manual de Operacionalização do SPCE - cadastro, Eleições 2018.

Disponible en: http://www.justicaeleitoral.jus.br/arquivos/tse-manual-de-operacionalizacaodo-spce-cadastro-v2 Acceso el: 22 ago. 2018.

Tribunal Superior Eleitoral. Resolução N²3.546, de 18 de dezembro de 2017. Disponible en: http://www.tse.jus.br/legislacao-tse/res/2017/RES235462017.html Acceso el: 26 ago. 2018.

Tribunal Superior Eleitoral. Perguntas Frequentes - Fundo Partidário. Disponible en: http://www.tse.jus.br/partidos/fundo-partidario-1/perguntas-frequentes-fundo-partidario . Acceso el: 22 ago. 2018.

\section{RESUMEN BIOGRÁFICO}

\section{Juedir Viana Teixeira}

Doctorado en administración por la UNAM. Maestría en Gestión Estratégica de Negocios - Universidad Nacional de Misiones - UNaM. Profesor universitario de la FGV. Línea de investigación: Control y Administración Financiera.

\section{Lamenha, Artur Angelo Ramos}

Doctorando en administración por la UNaM. Maestría en Gestión Pública, UFPE. Profesor de la Faculdade de Economia, Administração e Contabilidad de la Universidade Federal de Alagoas UFAL y del CESMAC. Analista en Gestión de la Fundación Instituto Brasileño de Geografía y Estadística IBGE. Línea de investigación: Control y Administración Financiera.

\section{Matheus Costa Correa}

Licenciado en ciencias contables por la Universidad Federal de Alagoas.

\section{João Vinicius Santos Correia de Melo}

Licenciado en ciencias contables por la Institución SEUNE.

\footnotetext{
"Visión de Futuro" Año 17, Volumen No 24 N², Julio - Diciembre 2020 - Pág. 1 - 19

URL de la Revista: http://visiondefuturo.fce.unam.edu.ar/index.php/visiondefuturo/index

URL del Documento: https://visiondefuturo.fce.unam.edu.ar/index.php/visiondefuturo/issue/view/18

ISSN 1668 - 8708 - Versión en Línea

E-mail: revistacientifica@fce.unam.edu.ar
} 